\title{
Valproic Acid Decreases Cell Proliferation and Color Preference in the Zebrafish Larvae
}

\author{
Bongkyu Lee, Sujeong Lee, Miyoung Choi, Chang-Joong Lee* \\ Department of Biological Sciences, Inha University, Incheon, Korea \\ Email: *changleeinha@gmail.com
}

How to cite this paper: Lee, B., Lee, S., Choi, M. and Lee, C.-J. (2017) Valproic Acid Decreases Cell Proliferation and Color Preference in the Zebrafish Larvae. Journal of Biosciences and Medicines, 5, 56-66. https://doi.org/10.4236/jbm.2017.512007

Received: October 31, 2017

Accepted: December 5, 2017

Published: December 8, 2017

Copyright ( 92017 by authors and Scientific Research Publishing Inc. This work is licensed under the Creative Commons Attribution International License (CC BY 4.0).

http://creativecommons.org/licenses/by/4.0/

(c) (i) Open Access

\begin{abstract}
Valproic acid (VPA) is widely used as an antiepileptic drug or mood stabilizer. In this study, we evaluated the effects of treatment with $2 \mathrm{mM}$ VPA for $3 \mathrm{~h}$ on cell proliferation in the telencephalic area of zebrafish larvae using bromodeoxyuridine (BRDU) to label dividing cells. It was demonstrated that 2 $\mathrm{mM}$ VPA exposure for $3 \mathrm{~h}$ at 2 and 3 days post-fertilization (dpf) larvae decreased cell proliferation in the telencephalic area of $5 \mathrm{dpf}$ larvae. The reduced cell proliferation was not restored at $10 \mathrm{dpf}$ larvae. The quantitative real-time PCR (qRT-PCR) data indicated that mRNA expression levels of WNT signaling pathway-related factors such as $\beta$-catenin, LEF 1 , and gsk $3 \beta$ were altered in the zebrafish larvae treated with $2 \mathrm{mM} \mathrm{VPA}$ at 2 and 3 pdf. It was also demonstrated that $2 \mathrm{mM}$ VPA exposure affected color preference of the zebrafish larvae, reducing blue color preference at $5 \mathrm{dpf}$ larvae. The altered color preference was restored at $10 \mathrm{dpf}$ larvae. These results suggest that VPA exposure may cause molecular, cellular, and behavioral alterations in early developmental stage of the zebrafish.
\end{abstract}

\section{Keywords}

BRDU, Valproic acid, Color preference, $\beta$-catenin, Zebrafish

\section{Introduction}

Exposure to valproic acid (VPA) during the prenatal and postnatal period is known to have some deleterious effects on the brain development and behavior. Recently, it has been reported that VPA exposure to pregnant mice alters BNDF mRNA and protein levels in the fetal mouse brain, and may cause abnormal brain development [1]. Various behavioral deficit such as decreased raising and hole-poking along with increased locomotor activity in novel environments and increased anxiety were also found postnatally in rats prenatally exposed to VPA 


\section{[2] [3] [4].}

Accumulating studies have shown that extensive reduction of neurogenesis in the developing brain may be involved in a variety of neurological functions in adult mice and humans [5] [6]. For example, severe cell proliferation defects are present in the developing neocortex, dentate gyrus, and cerebellum of mouse of Down Syndrome (DS) models [7], and the hippocampal and cerebellar regions of human fetuses with DS [8]. In the brain of zebrafish larvae cell proliferation and neurogenesis actively occur in diverse areas and are affected by external factors such as treatment with pentylenetetrazol, a GABA receptor blocker [9]. Therefore, the zebrafish is an appropriate model for researching behavioral consequences in adulthood that may be caused by alterations of cell proliferation in the brain during early development stages.

WNT signaling factors such as $\beta$-catenin and LEF1 are involved in regulation of cell proliferation in the mammalian brain [10]. A nuclear mediator of wnt signaling, LEF1 accelerates cell proliferation in the developing forebrain of the mouse [11]. These findings indicate the association between alterations in the WNT signaling gene expression and changes in cell proliferation following VPA exposure. In this study, the effects of VPA on the brain development and cell proliferation were studied in the telencephalic area of the zebrafish larvae. Furthermore, modification of color preference was also examined in the VPA-treated larvae.

\section{Materials and Methods}

\subsection{Animals}

Adult zebrafish (around $2.5 \mathrm{~cm}$ in length) were purchased from a local fish shop (Incheon, South Korea) and maintained at $28.5^{\circ} \mathrm{C} \pm 1.0^{\circ} \mathrm{C}$ with a 14 -h light/10-h dark cycle in aquariums as described previously [12].

\subsection{Immunostaining}

VPA (Sigma-Aldrich) was dissolved in distilled water at a concentration of $1 \mathrm{M}$, and then diluted to final concentrations of $2 \mathrm{mM}$ in containers of aquarium water. Zebrafish larvae ( 2 and 3 days postfertilization [dpf]) were placed for $3 \mathrm{~h}$ in aquarium water containing $2 \mathrm{mM}$ VPA. For the control experiment, age-matched larvae were placed in normal aquarium water during the corresponding period. After terminating the VPA treatment, the larvae were maintained for $12 \mathrm{~h}$ in aquarium water containing $10 \mathrm{mM}$ 5-bromo-2'-deoxyuridine (BRDU; Sigma-Aldrich).

All larvae were fixed with 4\% PFA in $0.01 \mathrm{M}$ PBS immediately after termination of the BRDU treatment, and cryoprotected overnight in $30 \%$ sucrose at $4{ }^{\circ} \mathrm{C}$. The larvae were then sectioned with a cryostat (CM1800; Leica, Wetzlar, Germany) in the coronal plane at a thickness of $10 \mu \mathrm{m}$. The sections were mounted onto coated slides (Matsunami Glass Ind., Ltd., Osaka, Japan), and stored at $-20^{\circ} \mathrm{C}$ until further use. 
Double-labeling was conducted to detect colocalization of BRDU and proliferating cell nuclear antigens (PCNA, a cell proliferation marker). Sections were rinsed in $0.1 \%$ Triton X-100 in PBS (PBS-T) and blocked with $10 \%$ normal goat serum (Jackson Immuno Research, West Grove, PA, USA) in 0.1\% PBS-T. After washing, the sections were incubated overnight at $4^{\circ} \mathrm{C}$ in a cocktail containing antibodies specific for anti-rat monoclonal BRDU (1:1000; Abcam, Cambridge, UK) and PCNA (1:300; DAKO). The sections were incubated for $1 \mathrm{~h}$ at room temperature in a mixture of secondary antibodies including goat anti-rat IgG conjugated to Alexa Flour 594 (1:1000; Molecular Probes) to detect BRDU and goat anti-mouse IgG conjugated to Alexa Flour 488 (1:1000; Molecular Probes) to visualize PCNA. The slides were analyzed and photographed with ZEN Light Edition software and a Zeiss LSM 510 META (Carl Zeiss, Jena, Germany).

For the quantitative analyses, all cells stained for BRDU and PCNA in the pallium and dorsal subpallium of the telencephalic area were counted under 200X magnification using an Olympus IX71 inverted microscope. Data are expressed as the mean \pm S.E.M and were analyzed with an ANOVA followed by post hoc Tukey's tests unless otherwise stated. P-values $<0.05$ were considered significant.

\subsection{Color Preference Tests}

For measurements of color preference in the zebrafish larvae, a color maze kit $(8.2 \mathrm{~cm}$ long $\times 12.4 \mathrm{~cm}$ wide $\times 2.1 \mathrm{~cm}$ high) was subdivided into eight compartments, each compartment with divided into two colors (blue and yellow) by color sleeves. The color preference of the zebrafish larvae was monitored using a digital camera; fish's position (blue or yellow sleeve) was monitored every minute for $1 \mathrm{~h}$. The data were expressed as the means \pm S.E.M and subjected to ANOVA, followed by post hoc Tukey's tests.

For the experiment, ten zebrafish larvae ( 5 and $10 \mathrm{dpf}$ ) were placed in a compartment of color maze filled with normal aquarium water $(4 \mathrm{ml})$ on an illumination box.

\subsection{Whole-Mount Skeletal Staining}

Cartilage of the zebrafish larvae was stained as described previously [13]. The larvae were fixed at $10 \mathrm{dpf}$ with $4 \%$ PFA in $0.01 \mathrm{M}$ PBS ( $\mathrm{pH}$ 7.4) for $4 \mathrm{~h}$ at room temperature, washed in $0.1 \%$ PBS-T, and stained overnight with $0.1 \%$ Alcian blue 8GX (Sigma-Aldrich) in $80 \%$ ethanol $/ 20 \%$ acetic acid. For clarification, the larvae were treated with $1 \% \mathrm{KOH} / 3 \% \mathrm{H}_{2} \mathrm{O}_{2}$ for $6 \mathrm{~h}$, followed by digestion for 15 min with $0.02 \%$ trypsin (Sigma-Aldrich) dissolved in PBS. The larvae were then rehydrated in $70 \%, 50 \%$, and $30 \% \mathrm{EtOH} / 0.01 \mathrm{M} \mathrm{PBS}$, cleared in $30 \%$ glycerol/0.01 M PBS, and stored in 100\% glycerol. Larvae stained with Alcian blue were dissected and flat-mounted. The cartilage was examined with a Leica MZ75 microscope at 50X magnification and images were captured by a Nikon D200 camera (Nikon, Tokyo, Japan). 


\subsection{Quantitative Real-Time PCR (qRT-PCR)}

The heads of 50 larvae were flash-frozen on dry ice at 12 h, $2 \mathrm{~d}, 3 \mathrm{~d}, 7 \mathrm{~d}$, and $8 \mathrm{~d}$ of recovery in normal water after $2 \mathrm{mM}$ VPA treatment. Zebrafish larvae heads were lysed in TRIzol reagent (Invitrogen), and total RNA was isolated following the manufacturer's protocols. RNA was then treated with DNase I (Promega) to eliminate genomic DNA contamination and further purified using the RNeasy mini kit (Qiagen) following the manufacturer's protocols.

qRT-PCR was performed with a 7300 Real-Time PCR System (Applied Biosystems, Foster City, CA, USA) with SYBR Green I and Taq polymerase. The following primers were used: $\beta$-actin, forward (5'-ATG GAT GAG GAA ATC GCT GCC-3') and reverse (5'-CTC CCT GAT GTC TGG GTC GTC-3'); hsp70, forward (5'-GCA GGC CGC CAT CCT CAT-3') and reverse (5'-GTA CTC CTC TTT ATC TGC CAG-3'); $\beta$-catenin, forward (5’-GAC ATC AAC GTG GTG ACG TGT-3') and reverse (5'-CAT CCT GGT GTC TGG ATG TGA-3'); LEF1, forward (5'-GAG GGA AAA GAT CCA GGA AC-3') and reverse (5'-AGG TTG AGA AGT CTA GCA GG-3'); and gsk $3 \beta$, forward (5'-TGG CCT ACA TCC ATT CCT TTG-3’) and reverse (5’-GTG GCT CCA AAG ATG AGT TCG-3’).

\section{Results}

\subsection{The Number of BRDU- and PCNA-Positive Cells Was Reduced by 2 mM VPA}

The number of BRDU-positive cells in the telencephalic area of zebrafish treated with $2 \mathrm{mM}$ VPA at 2 and $3 \mathrm{dpf}$ was reduced significantly to $43.2 \%$ and $43.5 \%$ of the control at $12 \mathrm{~h}$ after BRDU injection ( $\mathrm{p}<0.01, \mathrm{n}=8$ ) (Figure 1 (a) and Figure $1(\mathrm{~b})$ ). The number of PCNA-positive cells was also significantly reduced to $34.0 \%$ and $32.6 \%$ of that found in the control $(\mathrm{p}<0.01, \mathrm{n}=8$ ) (Figure $1(\mathrm{c})$ ). To find out whether the suppressive effect of VPA on cell proliferation is lasting, BRDU- or PNCA-positive cells in the telencephalic area of larvae that had been treated with $2 \mathrm{mM} \mathrm{VPA}$ for $3 \mathrm{~h}$ at 2 and $3 \mathrm{dpf}$ were measured at 5 and $10 \mathrm{dpf}$. The numbers of BRDU- or PCNA-positive cells measured $12 \mathrm{~h}$ following BRDU treatment were not significantly different at 2, 3, 5 and $10 \mathrm{dpf}$ in the control. However, the numbers of BRDU- or PCNA-positive cells were significantly lower in the $2 \mathrm{mM}$ VPA-treated larvae of 2,3,5, and $10 \mathrm{dpf}$ compared to the age-matched controls (Figure 1).

\subsection{Expression Levels of Hsp70, $\beta$-Catenin, LEF1, and Gsk3 $\beta$ mRNA Were Altered by 2 mM VPA}

Expression of hsp70, $\beta$-catenin, LEF1, and gsk3 $\beta$ mRNA was measured $2,3,5$, and $10 \mathrm{dpf}$ in the zebrafish larvae that had been treated with $2 \mathrm{mM}$ VPA for $3 \mathrm{~h}$ at 2 and 3 dpf. qRT-PCR results showed that the expression of $\beta$-actin, a control gene, was not different between the control and VPA-treated zebrafish (data not shown). The expression levels of hsp70 increased 3- and 3.5-fold relative to the control $12 \mathrm{~h}$ after the VPA treatment at 2 and $3 \mathrm{dpf}$, respectively $(\mathrm{p}<0.01, \mathrm{n}=$ 
(a)
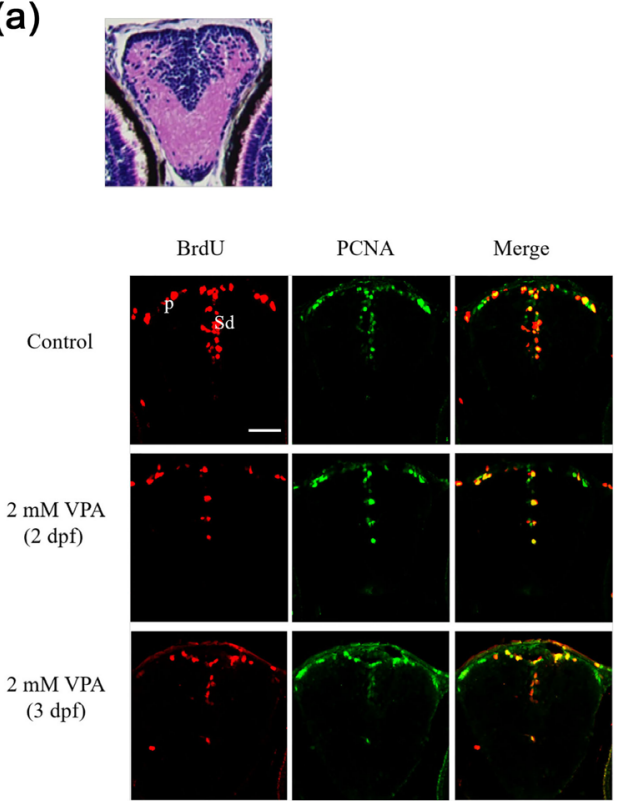

(b)

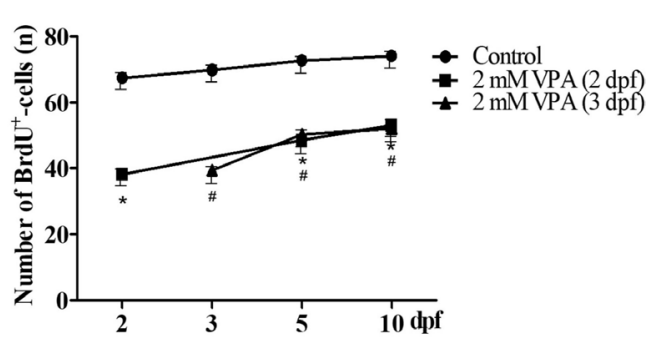

(c)

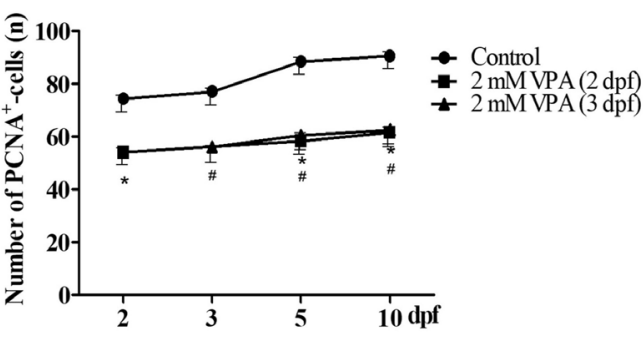

Figure 1. Reduced number of BRDU- and PCNA-positive cells in the zebrafish larvae treated with $2 \mathrm{mM}$ VPA: (a) A representative hematoxylin and eosin stained section of the telencephalic area of zebrafish larvae $(5 \mathrm{dpf})$ is shown at the top. Fluorescence microscope images show the immunostaining patterns corresponding to BRDU (red) and PCNA (green); (b) Quantification of BRDU-positive cells in the pallium (P) and dorsal subpallium (Sd); (c) Quantification of PCNA-positive cells in the pallium (P) and dorsal subpallium (Sd). Data were expressed as the means \pm S.E.M and were analyzed via post hoc Tukey's multiple comparison tests. ${ }^{*} \mathrm{P}<0.01$ (VPA-treated at $2 \mathrm{dpf}$ ); ${ }^{\#} \mathrm{P}<0.01$ (VPA-treated at $3 \mathrm{dpf}$ ) compared to the control; Scale bar $=0.5 \mathrm{~mm}$.

3). The levels of hsp70 mRNA decreased by $80.6 \%$ and $53.7 \%$ of the 2 dpf larvae treated with VPA in the 5 and 10 dpf larvae, respectively $(\mathrm{p}<0.01, \mathrm{n}=3$ ) (Figure 2(a)). Similarly, the levels of hsp70 mRNA decreased by $47.8 \%$ and $37.5 \%$ of the $3 \mathrm{dpf}$ larvae treated with VPA in the 5 and $10 \mathrm{dpf}$ larvae, respectively $(\mathrm{p}<0.01, \mathrm{n}=3$ ) (Figure $2(\mathrm{~b})$ ). $\beta$-catenin mRNA expression was not significantly different from the control $12 \mathrm{~h}$ after VPA treatment, but gradually decreased by $31.6 \%$ and $53.1 \%$ of the control in the larvae treated with VPA at 2 dpf, and by $45.7 \%$ and $56.2 \%$ of the control in the larvae treated with VPA at 3 dpf when measured at 5 and $10 \mathrm{dpf}$, respectively $(\mathrm{p}<0.01)$ (Figure $2(\mathrm{c})$ and Figure 2(d)). LEF1 mRNA levels increased by $18.4 \%$ and $35.6 \%$ of the control 12 $\mathrm{h}$ after VPA treatment at 2 and $3 \mathrm{dpf}$. LEF1 mRNA levels gradually decreased by $40.6 \%$ and $49.7 \%$ of the control in the larvae treated with VPA at $2 \mathrm{dpf}$, and by $20.4 \%$ and $60.8 \%$ of the control in the larvae treated with VPA at $3 \mathrm{dpf}$ when measured at 5 and $10 \mathrm{dpf}$, respectively $(\mathrm{p}<0.01)$ (Figure $2(\mathrm{e})$ and Figure $2(\mathrm{f})$ ). The expression levels of gsk $3 \beta$ were not significantly different from the control $12 \mathrm{~h}$ after the VPA treatment at $2 \mathrm{dpf}$, but gsk $3 \beta$ mRNA expression increased by $16.4 \%$ in the VPA-treated zebrafish of $10 \mathrm{dpf}$ relative to the control $(\mathrm{p}<0.01, \mathrm{n}$ = 3) (Figure $2(\mathrm{~g})$ ). In the VPA-treated larvae at $3 \mathrm{dpf}$ gsk $3 \beta$ mRNA expression significantly increased by $19.5 \%$ of the control when measured at $5 \mathrm{dpf}$, respectively $(\mathrm{p}<0.01, \mathrm{n}=3)$ (Figure $2(\mathrm{~h})$ ). 


\subsection{Cranial Malformation Was Not Observed in the VPA-Treated Larvae}

Evaluation of the cartilage structures showed that the size and shape of the vis-

(a)

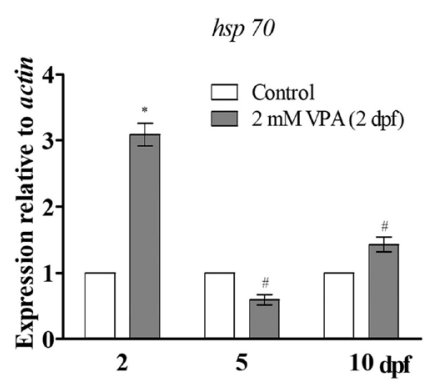

(c)

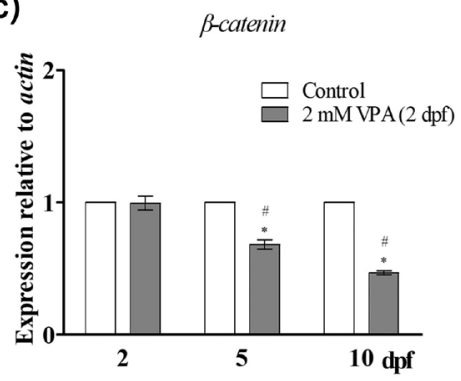

(e)

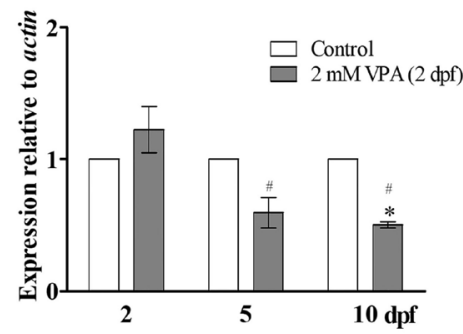

(g)

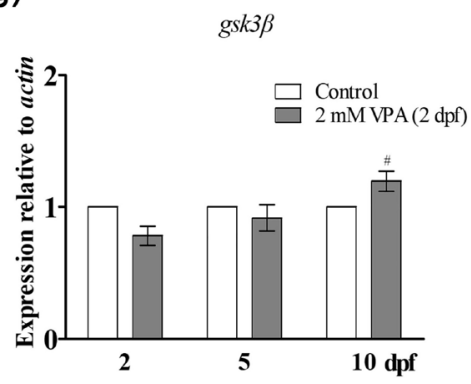

(b)

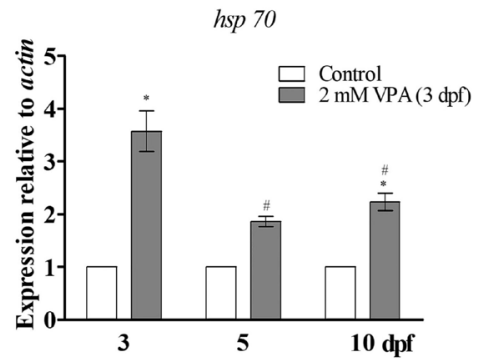

(d)

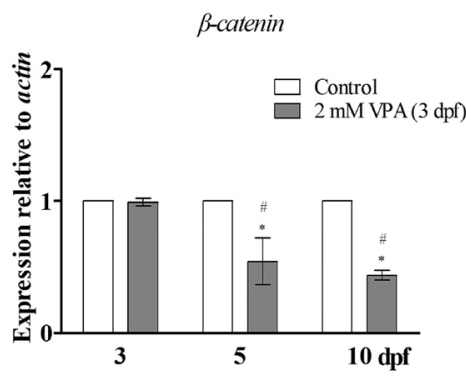

(f)

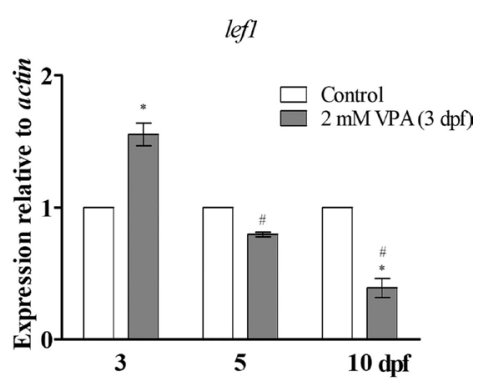

(h)

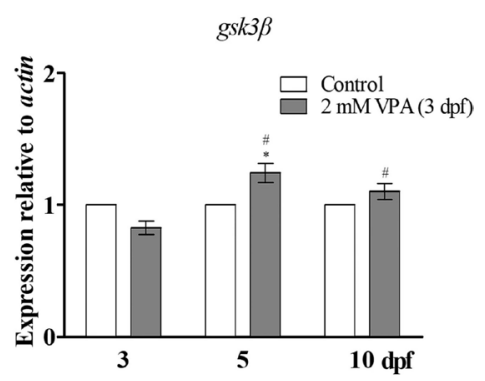

Figure 2. mRNA expression of hsp70, $\beta$-catenin, LEF1, and gsk $3 \beta$ in the zebrafish larvae treated $2 \mathrm{mM}$ VPA at 2 and $3 \mathrm{dpf:}((\mathrm{a}),(\mathrm{c}),(\mathrm{e}),(\mathrm{g}))$ Expression levels of hsp70, $\beta$-catenin, LEF1, and gsk $3 \beta$ mRNA zebrafish larvae treated with $2 \mathrm{mM}$ VPA at 2 dpf compared to the control; ((b), (d), (f), (h)) Expression levels of hsp70, $\beta$-catenin, LEF1, and gsk $3 \beta$ mRNA zebrafish larvae treated with $2 \mathrm{mM}$ VPA at $3 \mathrm{dpf}$ compared to the control. The data were expressed as the means \pm S.E.M and were analyzed with Student's t-tests along with post hoc Tukey's multiple comparison tests. ${ }^{*} \mathrm{P}<0.01$ versus the control at each time point (Student's t-tests); ${ }^{*} \mathrm{P}<0.01$ compared to the 2 or $3 \mathrm{~d}$ group (post hoc Tukey's tests). 
(a)

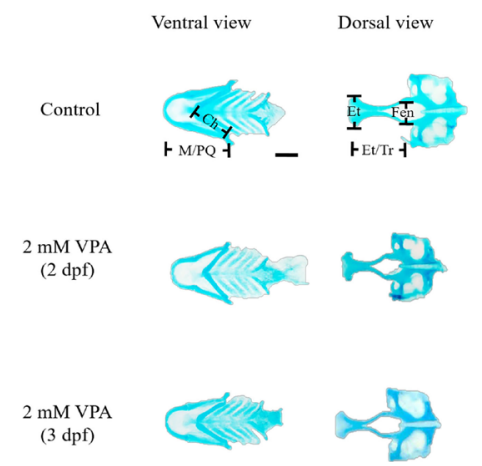

(b)

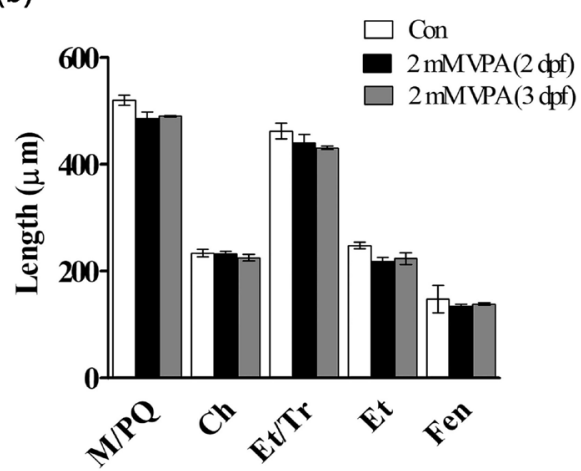

Figure 3. Effects of $2 \mathrm{mM}$ VPA on craniofacial development in the zebrafish larvae: (a) Image of Alcian blue staining of the control and VPA-treated larvae of $10 \mathrm{dpf}$. Meckel's and palatoquadrate cartilage $(\mathrm{M} / \mathrm{PQ})$, ceratohyals $(\mathrm{Ch})$ cartilage were clearly identified in the neurocranium (left); ethmoid plate and trabeculae (Et/Tr), ethmoid plate (Et), and fenestra (Fen) in viscerocranium (right) of the control and VPA-treated larvae; (b) Quantitative analysis of the M/PQ length, Ch length, Et/Tr length, Et width, and Fen width. Scale bar $=200 \mu \mathrm{m}, \mathrm{n}=5$.

cerocranium as well as neurocranium of the VPA-treated larvae were unaffected when measured at $10 \mathrm{dpf}$ (Figure 3(a)). The Meckel's and palatoquadrate cartilage $(\mathrm{M} / \mathrm{PQ})$, ceratohyals $(\mathrm{Ch})$, ethmoid plate and trabeculae (Et/Tr), ethmoid plate $(\mathrm{Et})$, and fenestra (Fen) were $520.3 \pm 2.8,234.4 \pm 3.4,462.8 \pm 4.4,248.4 \pm$ 3.1 , and $148.0 \pm 4.8 \mu \mathrm{m}$, respectively, in the control $(\mathrm{n}=5) ; 485.7 \pm 6.4,232.5 \pm$ 2.7, 440.1 $\pm 5.9,218.7 \pm 3.6$, and $135.1 \pm 1.5 \mu \mathrm{m}$ in the larvae treated with VPA at $3 \mathrm{dpf}(\mathrm{n}=5) ; 490.6 \pm 0.6,225.2 \pm 3.1,431.2 \pm 1.8,224.0 \pm 5.2$, and $138.8 \pm 1.5$ $\mu \mathrm{m}$ in the larval treated with VPA at $2 \mathrm{dpf}(\mathrm{n}=5)$. No significant differences in these elements were observed the three groups (Figure $3(\mathrm{~b})$ ).

\subsection{Color Preference Was Transiently Altered by 2mM VPA}

In the color preference test at $5 \mathrm{dpf}$, blue color preference for the control were measured $9.01 \pm 0.06$ and yellow color preference were $0.98 \pm 0.06(\mathrm{p}<0.01, \mathrm{n}=$ 7) (Figure 4(a)). In contrast, blue color preference in the larval treated with VPA at 2 and $3 \mathrm{dpf}$ significantly decreased to $5.17 \pm 0.24$ and $6.11 \pm 0.21$ and yellow color preference significantly increased to $4.82 \pm 0.24$ and $3.88 \pm 0.21$ for the $5 \mathrm{dpf}$ larvae, respectively ( $\mathrm{p}<0.01, \mathrm{n}=7$ ) (Figure $4(\mathrm{a})$ ). However, altered color preference was recovered at $10 \mathrm{dpf}$. Blue color preference in the control was measured to $7.11 \pm 0.03$ and yellow color preference was $2.92 \pm 0.02$ at 10 dpf $(n=8)$ (Figure $4(b))$. Similarly, blue color preference in the larval treated with VPA at 2 and $3 \mathrm{dpf}$ were $6.56 \pm 0.05$ and $6.81 \pm 0.15$ and yellow color preference were to $3.43 \pm 0.05$ and $3.18 \pm 0.15$, respectively $(\mathrm{p}<0.01, \mathrm{n}=8$ ) (Figure $4(b)$ ). Locomotion activity increased as zebrafish larvae grew with no significant difference between groups (data not shown).

\section{Discussion}

This study showed that $2 \mathrm{mM}$ VPA reduced cell proliferation in the telencephalic 
(a)

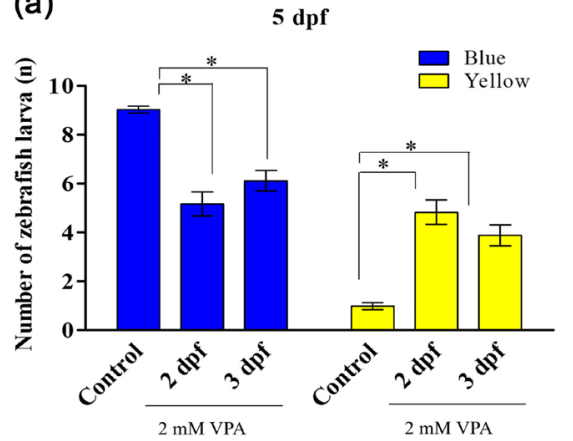

(b)

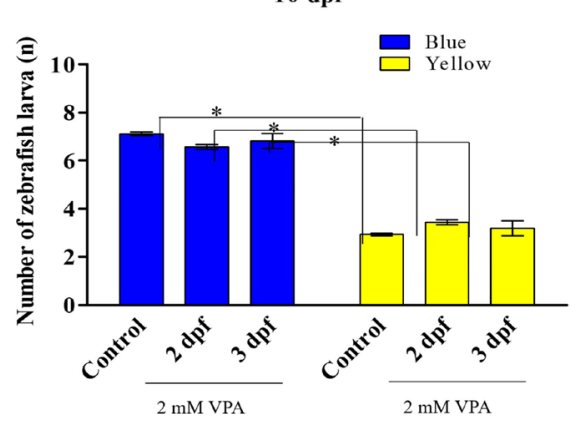

Figure 4. Altered color preference by $2 \mathrm{mM}$ VPA: (a) Color preference test measured at 5 dpf. Yellow color preference was increased in the zebrafish larvae treated with $2 \mathrm{mM}$ VPA at 2 and $3 \mathrm{dpf}$ compared to the control; (b) Color preference test measured at $10 \mathrm{dpf}$. Color preference was recovered in the zebrafish larvae treated with $2 \mathrm{mM}$ VPA. The data were expressed as the means \pm S.E.M and were analyzed via post hoc Tukey's multiple comparison tests. ${ }^{*} \mathrm{P}<0.01$ compared to the control.

area of zebrafish larvae. Expression levels of LEF1 and $\beta$-catenin mRNA, nuclear mediators of wnt signaling, were also decreased following treatment with $2 \mathrm{mM}$ VPA. LEF1 and $\beta$-catenin have been shown to increase cell proliferation in the developing brain of the mouse and neural stem cell [10] [11] [14]. In addition, a previous research has shown that VPA increases hsp70 protein levels in the rat cortical neurons [15]. Similarly, hsp70 mRNA levels were increased in the zebrafish brain treated with $2 \mathrm{mM}$ VPA for $3 \mathrm{~h}$ in this study.

It has been reported that young epilepsy patients suffered hyperammonemic encephalopathy following treatment with VPA for $1 \sim 2$ weeks [16]. The serum valproic acid level ranged $50 \sim 269.9 \mathrm{mg} / \mathrm{L}$, which roughly corresponds to $0.5 \sim$ $2.5 \mathrm{mM}$ [16] [17]. Our previous study has also shown that treatment with $2 \mathrm{mM}$ VPA induced learning impairments in the adult zebrafish [18]. In this study, therefore, $2 \mathrm{mM} \mathrm{VPA}$ was applied for $3 \mathrm{~h}$ in aquarium water in order to evaluate effects of $2 \mathrm{mM}$ VPA on cell proliferation and behavior of zebrafish larvae.

The decreased cell proliferation in the larvae of 5 and $10 \mathrm{dpf}$ treated with 2 $\mathrm{mM}$ VPA for $3 \mathrm{~h}$ at 2 and $3 \mathrm{dpf}$ is consistent with a decreased cell proliferation in the larvae treated with the same dose of VPA for $3 \mathrm{~h}$ at $5 \mathrm{dpf}$ [11]. An interesting difference is that the decreased cell proliferation was gradually recovered within 10 days following VPA treatment at $5 \mathrm{dpf}$, while it was not recovered following VPA treatment at 2 and $3 \mathrm{dpf}$. This discrepancy in the recovery of cell proliferation depending on the treatment time may be attributed to different expression patterns $\beta$-catenin and LEF1 mRNA in the two groups. Expression patterns of $\beta$-catenin and LEF1 mRNA were altered following VPA treatment at 2 and $3 \mathrm{dpf}$ larvae in this study. When $2 \mathrm{mM}$ VPA was treated at the 2 and $3 \mathrm{dpf}$ larvae, $\beta$-catenin and LEF1 expression was lower in the VPA-treated larvae than the control at $2 \sim 8 \mathrm{~d}$ following VPA treatment. In contrary, gsk $3 \beta$ mRNA expression was higher in the VPA-treated larvae. Conversely, when the same does of VPA was treated at the $5 \mathrm{dpf}$ larvae, $\beta$-catenin and LEF1 expression was higher in the VPA-treated larvae than the control $2 \sim 10 \mathrm{~d}$ following VPA treatment 
[11]. On the contrary, gsk $3 \beta$ mRNA expression was lower in the VPA-treated larvae.

The reduced cell proliferation in the brain didn't cause either the cranial malformation or abnormal locomotive activity in this study. Locomotive activity increased as the larvae grew, but it was not significantly different between the control and VPA-treated larvae. However, color preference was altered in the $5 \mathrm{dpf}$ larvae treated with $2 \mathrm{mM}$ VPA at 2 and $3 \mathrm{dpf}$. VPA-treated larvae showed a decreased blue color preference compared to the control. Interestingly, the color sense disorder has been reported from adolescent patient who underwent seizure treatment by carbamazepine (CBZ) and VPA [19].

\section{Conclusion}

VPA is known to detrimentally affect the embryonic and fetal development when a pregnant woman is exposed to it in pregnancy. Taken our studies together, $2 \mathrm{mM}$ VPA had molecular and cellular effects on the brain development of zebrafish larvae. Especially, VPA treatment at 2 and $3 \mathrm{dpf}$ reduced cell proliferation in the telencephalic area of zebrafish larvae of 5 and $10 \mathrm{dpf}$. In addition, it was also demonstrated that VPA exposure might cause visual deficits. Furthermore, VPA altered expression patterns of LEF1, $\beta$-catenin, and gsk $3 \beta$ RNA, which might underlie the reduced cell proliferation. Thus, our study suggests the possible cellular and molecular factors underlying detrimental effects of VPA on the brain development.

\section{Acknowledgements}

This research was supported by Basic Science Research Program through the National Research Foundation of Korea (NRF) funded by the Ministry of Education, Science and Technology (2012-0002753).

\section{References}

[1] Almeida, L.E.F., Roby, C.D. and Krueger, B.K. (2014) Increased BDNF Expression in Fetal Brain in the Valproic Acid Model of Autism. Molecular and Cellular Neurosciences, 59, 57-62. https://doi.org/10.1016/j.mcn.2014.01.007

[2] Sandhya, T., Sowjanya, J., and Veeresh, B. (2012) Bacopa monniera (L.) Wettst Ameliorates Behavioral Alterations and Oxidative Markers in Sodium Valproate Induced Autism in Rats. Neurochemical Research, 37, 1121-1131. https://doi.org/10.1007/s11064-012-0717-1

[3] Banerjee, A., Engineer, C.T., Sauls, B.L., Morales, A.A., Kilgard, M.P. and Ploski, J.E. (2014) Abnormal Emotional Learning in a Rat Model of Autism Exposed to Valproic Acid in Utero. Frontiers in Behavioral Neuroscience, 8, 387. https://doi.org/10.3389/fnbeh.2014.00387

[4] Fujimura, K., Mitsuhashi, T. and Takahashi, T. (2017) Adverse Effects of Prenatal and Early Postnatal Exposure to Antiepileptic Drugs: Validation from Clinical and Basic Researches. Brain and Development, 39, 635-643. https://doi.org/10.1016/j.braindev.2017.03.026

[5] Guidi, S., Bonasoni, P., Ceccarelli, C., Santini, D., Gualtieri, F., Ciani, E. and Barte- 
saghi, R. (2008) Neurogenesis Impairment and Increased Cell Death Reduce Total Neuron Number in the Hippocampal Region of Fetuses with down Syndrome. Brain Pathology (Zurich, Switzerland), 18, 180-197. https://doi.org/10.1111/j.1750-3639.2007.00113.x

[6] Contestabile, A., Fila, T., Ceccarelli, C., Bonasoni, P., Bonapace, L., Santini, D., Bar tesaghi, R. and Ciani, E. (2007) Cell Cycle Alteration and Decreased Cell Proliferation in the Hippocampal Dentate Gyrus and in the Neocortical Germinal Matrix of Fetuses with down Syndrome and in Ts65Dn Mice. Hippocampus, 17, 665-678. https://doi.org/10.1002/hipo.20308

[7] Chakrabarti, L., Galdzicki, Z. and Haydar, T.F. (2007) Defects in Embryonic Neuro Genesis and Initial Synapse Formation in the Forebrain of the Ts65Dn Mouse Model of down Syndrome. The Official Journal of the Society for Neuroscience, 27, 11483-11495. https://doi.org/10.1523/JNEUROSCI.3406-07.2007

[8] Guidi, S., Ciani, E., Bonasoni, P., Santini, D. and Bartesaghi, R. (2011) Wide Spread Proliferation Impairment and Hypocellularity in the Cerebellum of Fetuses with down Syndrome. Brain Pathology (Zurich, Switzerland), 21, 361-373. https://doi.org/10.1111/j.1750-3639.2010.00459.x

[9] Kim, Y., Lee, Y., Lee, K., Lee, T., Kim, Y. and Lee, C. (2010) Reduced Neuronal Proliferation by Proconvulsant Drugs in the Developing Zebrafish Brain. Neurotoxicology and Teratology, 32, 551-557. https://doi.org/10.1016/j.ntt.2010.04.054

[10] Pei, Y., Brun, S.N., Markant, S.L., Lento, W., Gibson, P., Taketo, M.M., Giovannini, M., Gilbertson, R.J. and Wechsler-Reya, R.J. (2012) WNT Signaling Increases Proliferation and Impairs Differentiation of Stem Cells in the Developing Cerebellum. Development (Cambridge, England), 139, 1724-1733.

https://doi.org/10.1242/dev.050104

[11] Galceran, J., Miyashita-Lin, E.M., Devaney, E., Rubenstein, J.L. and Grosschedl, R. (2000) Hippocampus Development and Generation of Dentate Gyrus Granule Cells Is Regulated by LEF1. Development (Cambridge, England), 127, 469-482.

[12] Lee, Y., Kim, Y., Yun, J. and Lee, C. (2013) Valproic Acid Decreases the Proliferation of Telencephalic Cells in Zebrafish Larvae. Neurotoxicology and Teratology, 39, 91-99. https://doi.org/10.1016/j.ntt.2013.07.004

[13] Walker, M. and Kimmel, C. (2007) A Two-Color Acid-Free Cartilage and Bone Stain for Zebrafish Larvae. Biotechnic \& Histochemistry, 82, 23-28. https://doi.org/10.1080/10520290701333558

[14] Qi, C., Zhang, J., Chen, X., Wan, J., Wang, J., Zhang, P. and Liu, Y. (2017) Hypoxia Stimulates Neural Stem Cell Proliferation by Increasing HIF- $1 \alpha$ Expression and Activating Wnt/ $\beta$-Catenin Signaling. Cellular and Molecular Biology (Noisy-Le-Grand, France), 63, 12-19. https://doi.org/10.14715/cmb/2017.63.7.2

[15] Marinova, Z., Ren, M., Wendland, J.R., Leng, Y., Liang, M., Yasuda, S., Leeds, P. and Chuang, D. (2009) Valproic Acid Induces Functional Heat-Shock Protein 70 via Class I Histone Deacetylase Inhibition in Cortical Neurons: A Potential Role of Sp1 Acetylation. Journal of Neurochemistry, 111, 976-987. https://doi.org/10.1111/j.1471-4159.2009.06385.x

[16] Cherian, K.A. and Legatt, A.D. (2017) Burst Suppression Pattern on Electroencephalogram Secondary to Valproic Acid-Induced Hyperammonemic Encephalopathy. Pediatric Neurology, 73, 88-91. https://doi.org/10.1016/j.pediatrneurol.2016.12.011

[17] Sousa, C. (2013) Valproic Acid-Induced Hyperammonemic Encephalopathy-A Potentially Fatal Adverse Drug Reaction. SpringerPlus, 2, 13. 
https://doi.org/10.1186/2193-1801-2-13

[18] Lee, Y., Kim, D., Kim, Y.H., Lee, H. and Lee, C.J. (2010) Improvement of Pentylenetetrazol-Induced Learning Deficits by Valproic Acid in the Adult Zebrafish. European Journal of Pharmacology, 643, 225-231.

https://doi.org/10.1016/j.ejphar.2010.06.041

[19] Verrotti, A., Scaparrotta, A., Cofini, M., Chiarelli, F. and Tiboni, G.M. (2014) Developmental Neurotoxicity and Anticonvulsant Drugs: A Possible Link. Reproductive Toxicology, 48, 72-80. https://doi.org/10.1016/j.reprotox.2014.04.005 